\title{
The Status and Factors of Sludge Hydrolysis Acidification Research
}

\author{
Yang zhan bin ${ }^{1, a}, Z^{2}$ haoyuxin ${ }^{1, b^{*}}$, yangjing ${ }^{1, c}$, zhangjunjun ${ }^{1, d}$ \\ ${ }^{1}$ Key Laboratory of Songliao Aquatic Environment, Ministry of Education, Jilin Jian zhu University, \\ Changchun 130118, China \\ a983201045@qq.com, bhitzyx@163.com, corresponding author

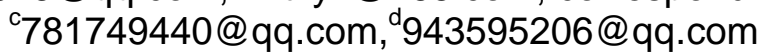

Keywords: Hydrolysis acidification; Factors; Pretreatment; Industrial wastewater

Abstract. With the development of civilization, various organic matters could be treated by hydrolysis and acidification process. Not only the high concentrations of refractory wastewater but also the large amount of sludge all could be handled by hydrolysis and acidification process with lower running cost and simple management. This paper reviewed the principles of hydrolysis acidification, and analyzed the effect factors of hydrolysis acidification and the present applying in China.

\section{Introduction}

With the sustainable development of social economy and the rapid development of industrialization, urban sewage treatment is also growing. Many industrial wastewater contained hard biochemical degradation of the pollution of toxic substances. The COD value is growing, but $\mathrm{C} / \mathrm{N}$ value is getting lower. The traditional aerobic biological treatment process is more and more difficult to meet the demand of nitrogen and phosphorus, so it is necessary to add carbon sources. But the external carbon source (such as volatile fatty acid VFAs) is not only a waste of resources, but also increased the operating costs of sewage treatment plants. On the other hand, with the increase of urban sewage treatment plant emissions, so that the sewage treatment plant sludge volume is also growing. At present, our country dry sludge yield of 300000 tons per year, and is growing at $10 \%$ a year, processing costs account for more than half of the sewage plant operation cost[1].Therefore, how to realize the sludge decrement harmless become an important problem of the sewage treatment plant.

Since 1980s, the research on anaerobic hydrolysis acidification has received more and more attention by domestic and foreign scholars. It has the characteristics of high organic removal rate, high concentration of wastewater, difficult degradation of wastewater, small treatment facilities, large processing capacity, low running cost, and can achieve the "water and mud" synchronous processing. At the same time, it also overcomes the shortcomings of anaerobic biological treatment process, and has a great role in the field of wastewater treatment.

\section{Principle of hydrolysis acidification}

Anaerobic biological treatment is divided into four stages: hydrolysis, acidification, acetic acid and methane production. The process of the hydrolysis stage refers to the process of the insoluble and the conversion of the polymer into SCOD. The stage of the production of methane is the conversion of the organic acids to the short chain fatty acids, $\mathrm{CO}_{2}$ and $\mathrm{H}_{2}$ in the production of acetic acid bacteria. These substances produce methane by methane - producing bacteria.

Hydrolysis acidification is the technology of controlling the anaerobic reaction in the hydrolysis and acidification stages. The process of hydrolysis acidification, organic macromolecules and cell extracellular enzymes is decomposed into small molecules. These molecules hydrolyzed products can be dissolved in water and through cell membrane synthesis of new cell material. 


\section{Influencing factors of sludge hydrolysis acidification}

Anaerobic hydrolysis acidification in the realization of sludge reduction and enhanced nitrogen and phosphorus removal aspects of a large extent by the pretreatment, $\mathrm{pH}$ value, temperature, $\mathrm{C} / \mathrm{N}, \mathrm{SRT}$ and other factors.

Pretreatment. The main organic matter in the sludge contained in the microbial cell membrane, and the membrane can prevent the cells by osmotic lysis. Cell wall containing peptide polymerized form peptidoglycan mesh structure can resist biodegradation ${ }^{[2]}$. Cells by itself is difficult to be dissolved or hydrolysis hydrolysis bacteria directly using. The slow rate of autolysis will delay subsequent anaerobic fermentation time so as to prolong the operation time of this part of the biological treatment. Therefore, we must carry on the pretreatment to the sludge to destroy the cell structure, and improve the efficiency of the sludge. VFAs pretreatment of excess sludge produced by physical, chemical, biological, and some of the combination of several.

Common physical methods include ultrasonic, microwave, heat treatment and etc. Ultrasound is considered the most effective way to crack the cell. High energy ultrasound cells can reach all of the decomposition, so that the production of VFA increased by 1.0 times ${ }^{[3]}$. Monyusiewicz's study ${ }^{[4]}$ found that VFA production doubled when sludge was treated by the use of frozen. Bougireret ${ }^{[5]}$ compared the effect of activated sludge treated by ultrasonic, ozone, pyrolysis and heat and found the effect of heat treatment was the best. In the combination contrast test, the ultrasonic wave was the highest in $6250 \mathrm{~kJ} / \mathrm{kg}$ and $9350 \mathrm{~kJ} / \mathrm{kJ}$.

Chemical methods include acid and alkali treatment. They are the main operation of domestic wastewater treatment plant especially industrial treatment plant and have the characteristics of simple operation and easy operation. Under alkaline condition, the organic substance in the sludge is more easy to release such as the VFAs. Lise et al ${ }^{[6]}$ used the solution of peroxide acetic acid to pre process the residual sludge. The yield of VFA increased with the increase of the dosage of the amount of the amount of acetic acid. The highest can reach more than ten times of the non pretreatment. Yuan Guanghuan et al. ${ }^{[7]}$ found that after the first acid alkali pretreatment method is better than single with alkali or After the first alkaline acid to obtain more VFAs .It is also found that the effect of single base treatment is best when the sludge reduction is the goal. Yu Huatang etc. ${ }^{[8]}$, using $50 \%$ sulfuric acid pretreatment + hydrolytic acidification + aerobic process bleaching wastewater treatment, water inlet COD, BOD, SS and chroma respectively 910, 255, $540 \mathrm{mg} / \mathrm{L}$, and 1100 times the debugging and running water after 2 years an average of $46,8,16 \mathrm{mg} / \mathrm{L}$ and eight times, removal rate reached $94.9 \%$, $96.9 \%, 97 \%$ and $99.3 \%$.

Hydrolytic acidification of amylase and protease can improve the dissolution of the sludge increased by $39.7 \%$ and $54.2 \%$, the combination of the two were better ${ }^{[9]}$.Lee et al. ${ }^{[10]}$ the study found,Alkaline protease was inoculated into the rest of the sludge, and the VFA was more than $60 \%$ in $\mathrm{PH}=10$ hydrolysis acidification.

Compared with the single mode, the combination method were easy to make the sludge crack, and produced in more VFAs. Xu et al ${ }^{[11]}$ found the effect of combined with ultrasound and ozone $\left(\mathrm{US} / \mathrm{O}_{3}\right)$ pretreatment was better than the separate use of sound, ozone. So the rate of hydrolysis acidification is faster and the obtaining of VFAs was more. Anteneh et al ${ }^{[12]}$ also found that the use of microwave and ultrasound combined with pretreatmentwas better than the effect of separate use.

PH value .The $\mathrm{pH}$ value was the main factor that affects microbial activity and enzyme activity. Most of the sludge anaerobic hydrolysis and fermentation of acid bacteria on the $\mathrm{pH}$ value of a larger range of hydrolysis and acidification of the bacteria can be successfully carried out in the range from 3.0 to10.0.Domestic surgical research scholars on the most suitable $\mathrm{pH}$ value controversy. Gomec et al. ${ }^{[13]}$ studies showed that the hydrolysis efficiency was high and the maximum degree of hydrolysis of the sludge can be obtained at the $\mathrm{pH}$ value of 6.5.But more and more studies have proved that the effect of sludge hydrolysis acidification was better in alkaline condition. Yuan et al. ${ }^{[14]}$ thank that the optimal conditions for the production of VFAs in the residual sludge hydrolysis acidification was about10.The research showed that the excess sludge at room temperature, $8 \mathrm{~d}$ fermentation time, 
under the condition of $\mathrm{PH}=6-10$, the VFAs production increases with $\mathrm{PH}$ value paid, fermentation to 8 days maximum COD $250 \mathrm{mg} / \mathrm{g}$ VSS volatile suspended solids (VSS).

Temperature. Temperature is the main controlling factor of sludge hydrolysis and acidification, which influences the growth rate of microbial metabolism. Hydrolytic acidification bacteria are very adaptable to temperature, and can survive at $10^{\circ} \mathrm{C} \sim 60^{\circ} \mathrm{C}$. The higher temperature was more suitable for the hydrolysis process. Ferreiro et al. ${ }^{[15]}$ found that the hydrolysis rate of sludge increased with the increase of temperature, and the VFAs increased with the increase of temperature at 25,10 and 35.Moser-Engeler et al ${ }^{[16]}$ studied the production of acid in the initial sink and excess sludge. It was found that the temperature at $20^{\circ} \mathrm{C}$ was $2-3$ times of $10^{\circ} \mathrm{C}$.

The radio of $\mathbf{C}$ and $\mathbf{N}$. In the process of sludge hydrolysis and acidification, $\mathrm{C} / \mathrm{N}$ is suitable for 10-20.Romano et $\mathrm{al}^{[17]}$ found that the effect of $\mathrm{C} / \mathrm{N}$ was the best when the radio value was 15.According to $\mathrm{C} / \mathrm{N}$, sludge is suitable for hydrolysis and acidification. Stroot et al ${ }^{[18]}$ began to study the combined effect of the primary sludge, excess sludge and solid organic wastes, and found that the combination of them can improve the efficiency of hydrolysis and acidification.

Sludge retention time (SRT). SRT is an important parameter in the design and operation of sludge treatment system. Feng et al ${ }^{[19]}$ Study the effect of SRT on the hydrolysis of excess sludge and the accumulation of VFAs. In practical application, the content of VFAs increased with the increase of SRT, which can be set according to the actual needs.

\section{The engineering application of hydrolytic acidification}

For environmental protection, industrial wastewater treatment is more important than urban sewage treatment.In recent years, it is found that hydrolysis acidification is widely used in industrial wastewater treatment by hydrolytic acidification as anaerobic and aerobic process.

Printing and dyeing waste water treatment. Printing and dyeing wastewater is big and the organic matter is complex. The BOD/COD is about 1 , which is very difficult to deal with ${ }^{[20]}$.Fu yongsheng et al [21] treated the printing and dyeing wastewater by hydrolytic acidification -UASB-SBR process and the problem of poor biodegradability of dyeing wastewater was solved better. Peng Jiwei et al ${ }^{[22]}$ found that the COD removal rate, the decolorization could be get about $97 \%, 95 \%$ respectively and the effluent water quality reached the first grade discharge standard. Xiang-song et al ${ }^{[23]}$ used coagulation sedimentation -ABR hydrolysis acidification -A2/O- aeration biological filter process to deal with comprehensive printing and dyeing wastewater, and the COD, $\mathrm{TN}$, BOD, TP, color removal rate was $87 \%, 93 \%, 94 \%, 68 \%, 76 \%$ respectively and the effluent water quality reached the first grade B standard.

Pharmaceutical wastewater treatment. The COD of pharmaceutical wastewater is high and it contend toxic and harmful substances. Wan Xing et al ${ }^{[24]}$ found that the COD, BOD, color removal rate was $94 \%, 96.1 \%$ and $94.3 \%$ respectively and the effluent water quality reached the first grade discharge standard when pharmaceutical wastewater was treated by the process of hydrolytic acidification - Biological Contact Oxidation - coagulation sedimentation.

Chemical industry wastewater treatment. Chemical wastewater is complex and contains many kinds of organic acids, aldehydes, ketones, esters, ethers and so on, which are highly toxic, especially benzene, phenol, cyanide and nitrobenzene. Zhang $\mathrm{Yu}^{[25]}$ found that the macromolecular heterocyclic compounds biodegradation process was used in chemical wastewater treatment and the small molecular organic acids were form. Wang Wei et al ${ }^{[26]}$ used the combination process of hydrolytic acidification - contact oxidation process to treat high concentration daily chemical wastewater.The removal rate of COD and BOD reached $98 \%$ and the drainage water quality reached the first grade discharge standard. 


\section{Conclusions}

With the accelerated pace of urbanization, urban sewage treatment capacity increased, the residual sludge treatment has become an important issue of environmental protection. Hydrolysis acidification achieved "water, mud treatment, sludge reduction and high concentration of VFAs, improve the C/N value of low biological city sewage denitrification efficiency, provide a reliable guarantee for the subsequent aerobic treatment.For wastewater containing a large number of large molecular substances, the impact load of the subsequent treatment process can be reduced by using the hydrolysis acidification pretreatment, and the SRT can be shortened, so that the wastewater treatment process can be optimized, and the utilization of sludge resource is realized.

Hydrolysis acidification process is also insufficient.Hydrolysis and acidification is only the initial decomposition of organic matter, the removal of COD is not high, the use of sewage treatment alone can not directly achieve the emission standards, it can only be used as a pretreatment of organic wastewater.The subsequent process of anaerobic methane fermentation and aerobic treatment can completely control the wastewater to meet the discharge standard, so the innovation process, which is used in combination with other processes, makes the water quality better, and will become the future research direction of scientific research workers.

\section{Acknowledgements:}

This work was financially supported by the National Natural Science Foundation of China(No.51208226) and by the Students Innovation Research Training Program of jilin province

\section{References:}

[1] Lu Haowen,Dai Ruihua, et al.The influence factors and research progress in Anaerobic Hydrolysis and Acidification of Sludge[J].Chemical Bulletin.2012,75(6):489-495.

[2] Ren Nanqi, Ma Fang, et al.Pollution control Microbiology (3 Edition)[M].Harbin Institute of Technology press.2006,14-16.

[3] Yan Y.Y.,Feng L.Y.,et al.Ultrasonic enhancement of waste tivated sludge hydrolysis andvolatile fatty acids accumulation at pH 10.0[J].Water Research.2010,44(11):3329-3336.

[4] Monyusiewicz,Lebiocka M.et al.Freezing/thawing effects on anaerobic digestion of mixed sewage sludge[J].Bioresource Technology.2010,101(10):3466-3473.

[5] Bougirer C., Albasi C..et al.Effect of ultrasonic, thermal and ozone pre-treatments on waste activated sludge solubilisation and anaerobic biodegradability[J].Chemical Engineering and Processing .2006(45): :711-718.

[6] Lise Appels,Ado V.A.,et al.Peracetic acds oxdation as an alternative pre-treatment for the anaerobic digestion of waste activated sludge Oringinal Research Article[J].Bioresource Technology.2011,102(5):4124-4130.

[7] Yuan Guanghuan, Zhou Xingqiu, Wu Jiandong.Impact of acid-alkali pretreatment on hydrolysis and acidification of excess sludge[J].Chinese Journal of Environmental Engineering.2013,7 (3) : 1145-1150.

[8] Yu Huatang,Zhang Qinyong, et al.treatment of Wastewater from Bleaching and Dyeing Industrial Area by Pretreatment / hydrolytic acidification / aerobic process [J].China Water \& wastewater.2008,24 (18): :75-77.

[9] Yang Q.,Luo K.,Li X.M.,et al.Enhanced efficiency of biological excess sludge hydrolysis under anaerobic digestion by additional enzymes[J].Bioresour.Technol.2010,101(9):2924-2930.

[10] Lee S.H.,Chung W.C.,et al.Effect of alkaline protease-producing Exiguobacterium sp.YSI inoculation on the solubilization and becterial communnity of waste activated sludge[J].Bioresour.Technol.2009,100(20):4597-4603. 
[11] Xu G.H.,Cheng S.H.,et al.Combination treatment of ultrasoumd and ozone for improving solubilization and anaerobic biodegradability of waste activated sludge[J].Journal of Hazardous Materials.2010,180(1-3)340-346.

[12] Anteneh M.Y., Siewhui C.,et al.Effect of ultrasonic, microwave and combined microwave-ultrasonic pretreatment of municipal sludge on anaerobic digester performance[J].Water Air Soil Pollut (2013) 224:1559.

[13] Gomec C.Y.,Speeece R.E.The role of PH in the organic material solubilization of domestic sludge in anaerobic digesrion[J].Wat.Sci.Tech..2003.48(3):143-150.

[14] Yuan H.Y, ChenY G, ZhangH X et al.Inproved Bioproduction of Short-Chain Fatty Acids(SCFAs)from excess sludgeunder alkaline conditions[J].Environ.Sci.Teachnol.2006.40(6):2025-2029.

[15] Ferreiro N.,Soto M..Anaerobic hydrolysis of primary sludge:influence of sludge concentration and temperature[J].Water Sci.Technol.2003,47(12):239-246.

[16] Moser-Engeler R.,Udert K.M.,Wild D..Siegrist Ptonducts from primary sludge for mentation and their suitability for nutrient removal[J].Water Sci.Technol.1998.38(1):265-273.

[17] Romano R.T.,Zhang R.H.Co-digestion of onion juice wasterwater sludge using an anaerobic mixed biofilm reacter[J].Bioresour.Technol.2008,99(3):631-637.

[18] Stroot P.,Mcmahon K.,Mackie R.Anaerobic codigestion of municipal solid waste and biosolids under various mixing conditions-I.digester performance[J].Water Res..2001,35(7):1804-1816.

[19] Feng L.Y.,Wang H.,Chen Y.G.Wang Q..Effect of solids retention time and temperature on waste activated sludge hydrolysis and short-chain fatty acids accumulation under alkaline conditions in continuous-flow reactors[J].Bioresour.Technol.2009,100(1):44-49.

[20] Wang Yadong.Advanced treatment technology and demonstration project of the high proportion printing and dyeing wastewater in urban wastewater treatment plant[D].Southeast China University.2008.

[21] $\mathrm{Fu}$ Yongsheng,Treatment of printing and dyeing wastewater by hydrolytic acidification -UASB-SBR combination process[J].Environmental Protection of Chemical industry.2002,22(3):157-157.

[22] Peng Jiwei, Shao Yunhai, Wang Junbo.treatment of textile printing and dyeing wastewater by improved Modified anaerobic- biological contact oxidation echnology [J].Industrial Water Treatment.2002,22(7):46-48.

[23] Xiang Song, Xu Lezhong, Li Cuihai, et al.Treatment of integrated printing and dyeing wastewater by hydrolytic acidification -A2/O- biological aerated filter process[J].Industrial Water Treatment.2013,33(5):25-28.

[24] Wan Xing, Huang Haiyan, Wan Jin Bao.Treatment of pharmaceutical wastewater by hydrolytic acidification biological contact oxidation coagulation sedimentation process[J].Water \& wastewater..2007,3(6):54-56.

[25] Zhang Yu, Tao Bo.Experimental study on facultative bioattached hydrolytic acidification in pretreatment of chemical industrial wastewater [J].Industrial water and wastewater.2008,39(4):40-42.

[26] Wang Wei, Wang Xiaojun, Zhou Xiangwu.Design and debugging examples of wastewater treatment engineering for cosmetics production[J].Environmental Engineering.2007,25(1):21-23. 